University of South Florida

DIGITAL COMMONS

Digital Commons @ University of

@ UNIVERSITY OF SOUTH FLORIDA

South Florida

Marine Science Faculty Publications

College of Marine Science

4-1985

\title{
Long Waves in the Equatorial Pacific Ocean
}

\author{
George Philander \\ Princeton University \\ David Halpern \\ NOAA \\ Donald Hansen \\ NOAA \\ Richard Legeckis \\ National Environmental Sattelite Data and Information Service \\ Laury Miller \\ University of Rhode Island
}

See next page for additional authors

Follow this and additional works at: https://digitalcommons.usf.edu/msc_facpub

\section{Scholar Commons Citation}

Philander, George; Halpern, David; Hansen, Donald; Legeckis, Richard; Miller, Laury; Watts, Randolph; Wimbush, Mark; Paul, Carl; Watts, Randolph; and Weisberg, Robert H., "Long Waves in the Equatorial Pacific Ocean" (1985). Marine Science Faculty Publications. 396.

https://digitalcommons.usf.edu/msc_facpub/396

This Article is brought to you for free and open access by the College of Marine Science at Digital Commons @ University of South Florida. It has been accepted for inclusion in Marine Science Faculty Publications by an authorized administrator of Digital Commons @ University of South Florida. For more information, please contact digitalcommons@usf.edu. 


\section{Authors}

George Philander, David Halpern, Donald Hansen, Richard Legeckis, Laury Miller, Randolph Watts, Mark Wimbush, Carl Paul, Randolph Watts, and Robert H. Weisberg 

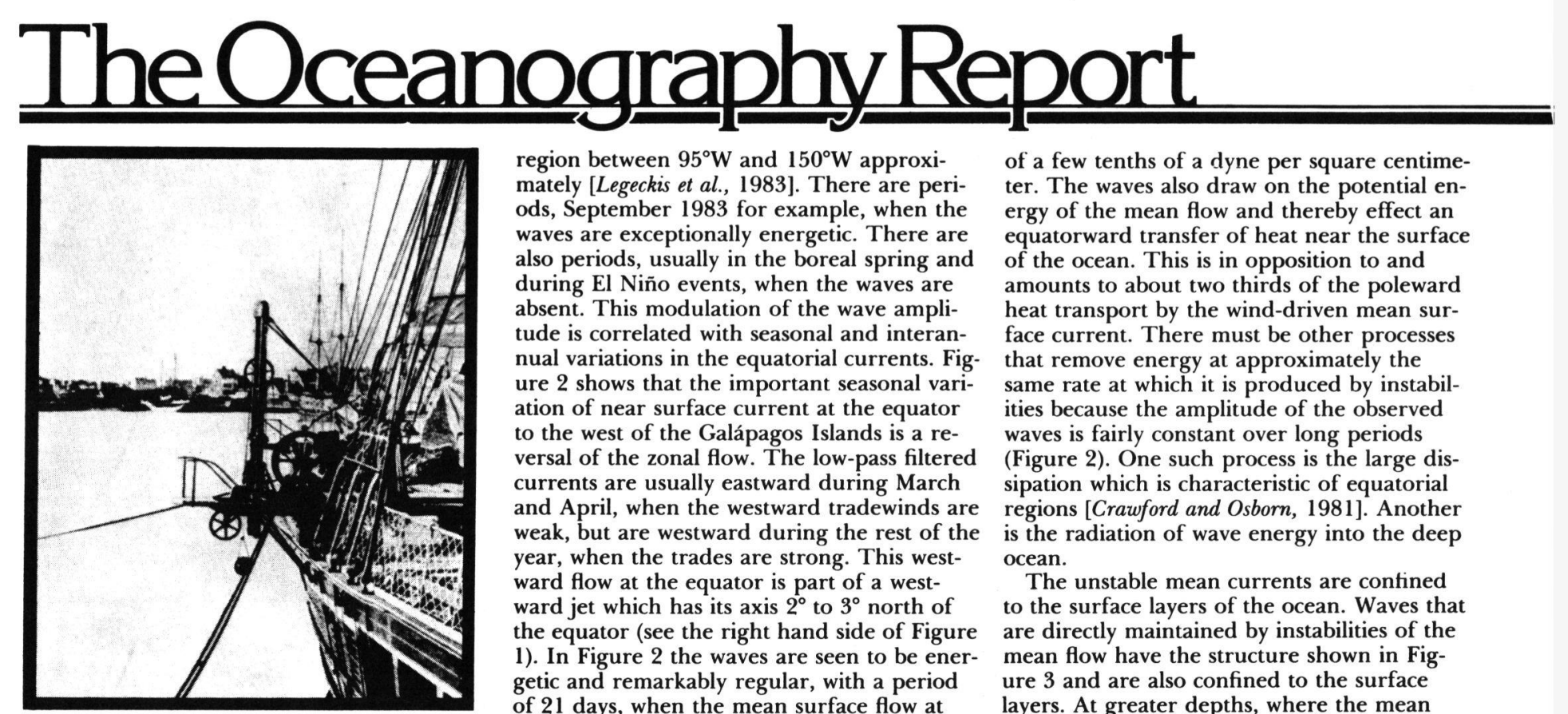

The U.S. Coast Survey steamer George S. Blake, ca. 1885, showing Sigsbee's modified Thompson piano wire sounding machine ready for action on the port side.

The focal point for physical, chemical, geological, and biological oceanographers.

Editor: David A. Brooks, Department of Oceanography, Texas A\&M University, College Station, TX 77843 (telephone: 409-845-5527).

\section{Long Waves in the Equatorial Pacific Ocean}

\section{George Philander, David Halpern, Donald Hansen, Richard Legeckis, Laury Miller, Carl Paul, Randolph Watts, Robert Weisberg, and Mark Wimbush}

\section{PAGE 154}

Westward traveling waves, with a period of 3 weeks and a wavelength of $\sim 1000 \mathrm{~km}$, are observed intermittently in the central and eastern equatorial Pacific Ocean (see cover). The waves were first detected in 1975 in satellite measurements of the sea surface temperature [Legeckis, 1977]. Since then, additional measurements (under the auspices of the NOAA program Equatorial Pacific Ocean Climate Studies (EPOCS)) with a variety of instruments-drifting buoys, current meters and temperature sensors on moorings, and inverted echo sounders-have provided considerable information about these waves and have confirmed the hypothesis that they are caused by instabilities associated primarily with the latitudinal shear of the surface currents near the equator [Philander, 1978a; Cox, 1980].

Sea surface temperature maps (Figure 1), obtained from infrared satellite measurements, sporadically show cusped waves in the region between $95^{\circ} \mathrm{W}$ and $150^{\circ} \mathrm{W}$ approximately [Legeckis et al., 1983]. There are periods, September 1983 for example, when the waves are exceptionally energetic. There are also periods, usually in the boreal spring and during El Niño events, when the waves are absent. This modulation of the wave amplitude is correlated with seasonal and interannual variations in the equatorial currents. Figure 2 shows that the important seasonal variation of near surface current at the equator to the west of the Galápagos Islands is a reversal of the zonal flow. The low-pass filtered currents are usually eastward during March and April, when the westward tradewinds are weak, but are westward during the rest of the year, when the trades are strong. This westward flow at the equator is part of a westward jet which has its axis $2^{\circ}$ to $3^{\circ}$ north of the equator (see the right hand side of Figure 1). In Figure 2 the waves are seen to be energetic and remarkably regular, with a period of 21 days, when the mean surface flow at the equator is westward, but the waves are absent when the flow is eastward. The waves are also absent during the interannual $\mathrm{El}$ Niño events, when the tradewinds collapse and the surface flow at the equator is eastward. This was the case between October 1982 and June 1983, for example.

The seasonal and interannual changes in the mean surface currents have a considerable effect on the stability properties of these currents. For example, the mean currents observed during the boreal spring and during El Niño events are stable, but the current observed during periods of intense trade winds are highly unstable. The intensity of the westward jet which has its axis near $2^{\circ} \mathrm{N}$ is a reliable indicator of how unstable the currents are. The calculated period and wavelength of the instabilities are in excellent agreement with the measurements. Measurements with satellite-tracked buoys that drift with the surface currents [Hansen and Paul, 1984] permit an estimate of the Reynolds' stress terms and confirm that the waves are caused primarily by a shear instability of the mean currents. The principal source of energy for the fluctuations is the kinetic energy of the mean currents. The braking effect on the mean flow is comparable to a change of surface wind stress of a few tenths of a dyne per square centimeter. The waves also draw on the potential energy of the mean flow and thereby effect an equatorward transfer of heat near the surface of the ocean. This is in opposition to and amounts to about two thirds of the poleward heat transport by the wind-driven mean surface current. There must be other processes that remove energy at approximately the same rate at which it is produced by instabilities because the amplitude of the observed waves is fairly constant over long periods (Figure 2). One such process is the large dissipation which is characteristic of equatorial regions [Crawford and Osborn, 1981]. Another is the radiation of wave energy into the deep ocean.

The unstable mean currents are confined to the surface layers of the ocean. Waves that are directly maintained by instabilities of the mean flow have the structure shown in Figure 3 and are also confined to the surface layers. At greater depths, where the mean currents are weak, the natural modes of oscillation of the ocean are equatorially trapped waves whose latitudinal structure is described by Hermite functions. Instabilities in the upper ocean, with a period of a few weeks, can excite downward propagating, equatorially trapped waves provided that

$$
\text { o }<-2 \Omega / a k
$$

where $k$ is the zonal wavenumber, $\sigma$ is the frequency of the waves, $\Omega$ is the rate of rotation of the earth, and $a$ is its radius. For a wavelength of $1000 \mathrm{~km}$ the period must exceed 25 days for downward propagating waves to be excited. At shorter periods the response attenuates with increasing distance from the surface layers [Philander, 1978b]. This explains why the decrease in energy levels with increasing depth, in spectra of crossequatorial velocity fluctuations (Figure $4 b$ ), is more pronounced at periods less than 25 days than it is at longer periods. In the case of the zonal velocity fluctuations the modest spectral peak at periods between 3 and 4 weeks is present at the surface only; it is absent at depths of $50 \mathrm{~m}$ and more (Figure $4 a$ ). This reflects the structure of the principal wave excited below the surface layers, namely, the equatorially trapped Rossby gravity

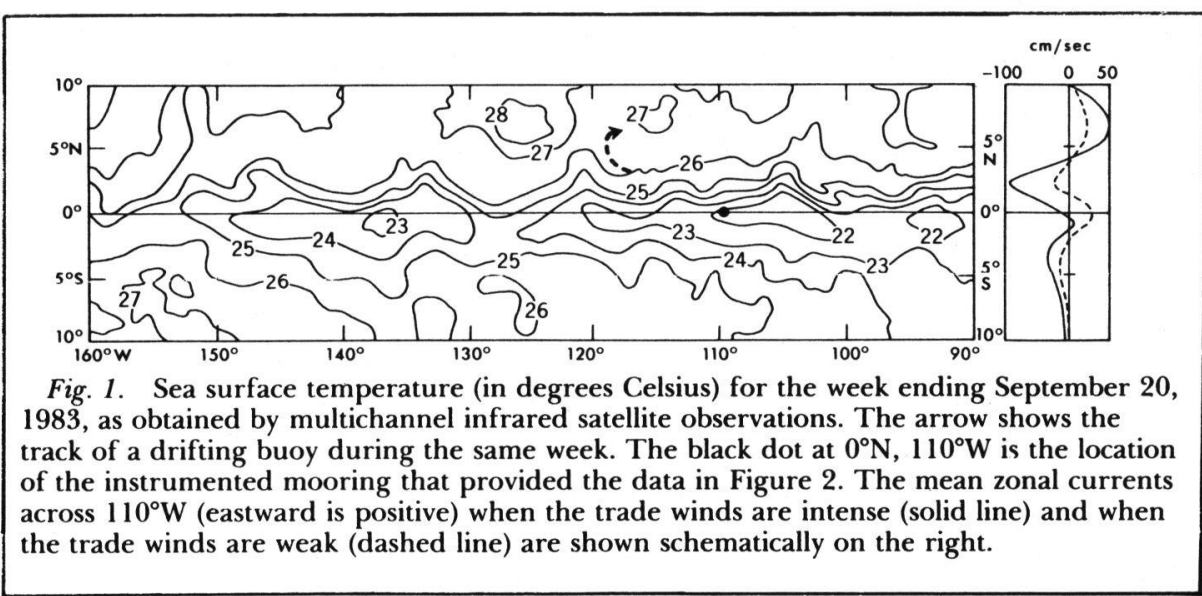




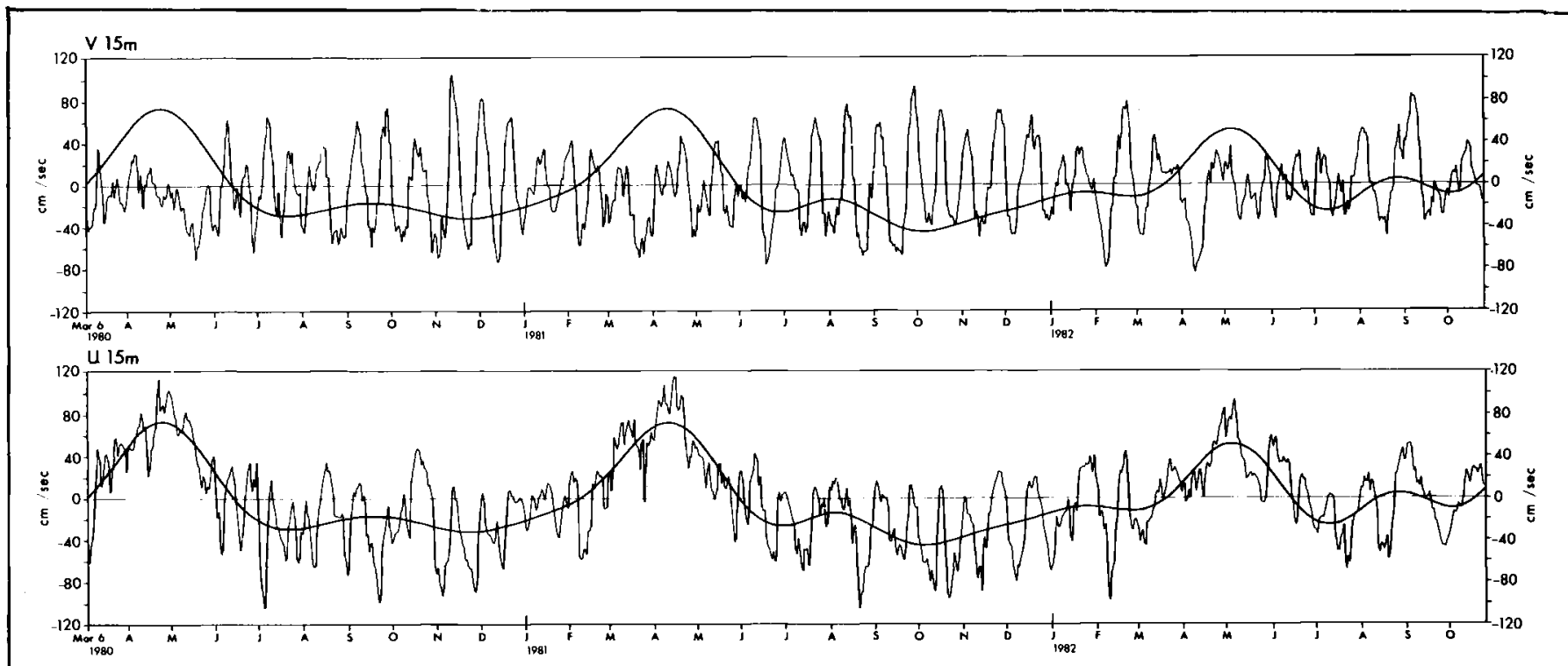

Fig. 2. Meridional $(v)$ and zonal $(u)$ velocity fluctuations at a depth of $15 \mathrm{~m}$ on the equator at $110^{\circ} \mathrm{W}$. The superimposed curve is the lowpass filtered zonal current. (The filter removes fluctuations with a period less than 100 days.) Note that the 3-week oscillations are most energetic when the mean current is westward $(u<0)$ [after Halpern, 1985].

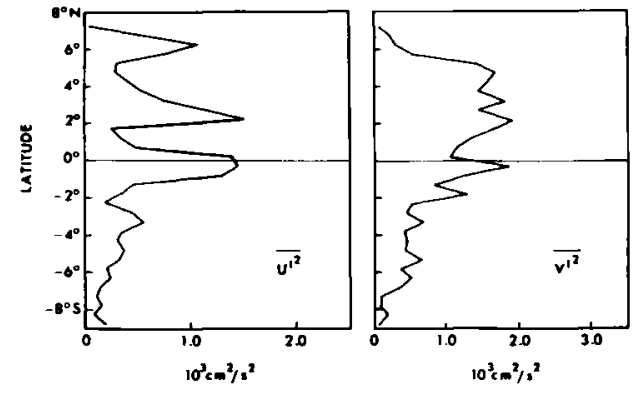

Fig. 3. Variance of the zonal and meridional velocity components as inferred from measurements with drifter buoys [after Hansen and Paul, 1984].
PERIOD (HOURS)

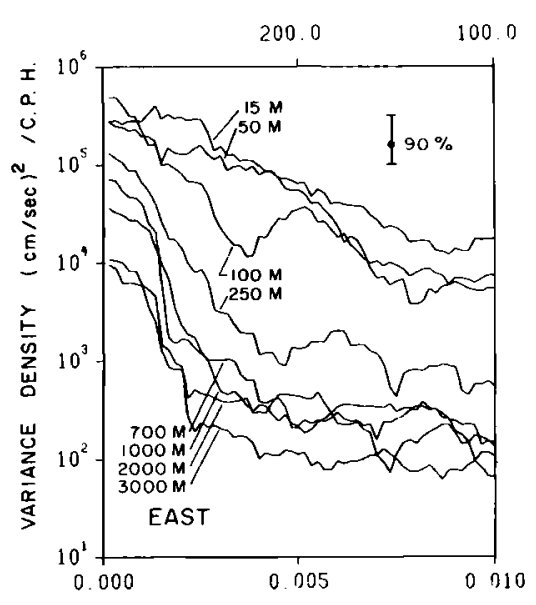

(a) FREQUENCY (C.P.H.)

Fig. 4. Spectra of $(a)$ zonal velocity fluctuations and $(b)$ meridional velocity fluctuations at different depths on the equator at $110^{\circ} \mathrm{W}$ (after R. H. Weisberg and D. Halpern, unpublished manuscript, 1985). wave. This mode is antisymmetrical about the equator so that meridional velocity fluctuations have a maximum but zonal fluctuations have a zero at the equator. Deep oceall medsurements in both the Pacific and Atlantic Oceans [Weisberg et al., 1979; Weisberg and Horigan, 1981] confirm the seasonal modulation, the dispersion relation, and the structure of this wave, which has westward phase speed but an eastward group velocity component. The motion observed at depth therefore originated in the surface layers to the west of the point of observation.

The Rossby gravity wave, which is the gravest latitudinal mode of the deep ocean, has a significant amplitude only within a few degrees latitude of the equator. Fluctuations observed poleward of $4^{\circ} \mathrm{N}$ and $4^{\circ} \mathrm{S}$ approximately correspond to the higher latitudinal modes of the deep ocean. The dispersion relation for these planetary modes indicates that their period increases as their latitudinal extent increases. This result is confirmed by measurements of the vertically averaged temperature of the water column at a number of locations along $110^{\circ} \mathrm{W}$ [Miller et al., 1985]. Spectra of the measurements show that the period of the most energetic fluctuations increases with increasing latitude from 30 days at $4.5^{\circ} \mathrm{N}$ to $\sim 70$ days at $10^{\circ} \mathrm{N}$. The principal source of energy for fluctuations at these long periods must be the surface winds because the instabilities in the surface layers of the ocean contribute principally to variability at periods between 3 and 4 weeks. There is a need for more data to document the latitudinal change in oceanic variability near the equator and to describe the vertical structure of this variability. Plans are being made to obtain such measurements during the next few years.

\section{References}

Cox, M. D., Generation and decay of 30 day waves in the numerical model of the Pacific, J. Phys. Oceanogr., 10, 11681-11686, 1980.

Crawford, W. R., and T. R. Osborn, Control of equatorial ocean currents by turbulent dissipation, Science, 212, 539-540, 1981.

Halpern, D., Low-frequency variability of the upper ocean near $0^{\circ} \mathrm{N}, 110^{\circ} \mathrm{W}, J$. Phys. Oceanogr., in press, 1985.

Hansen, D. V., and C. A. Paul, Genesis and effects of long waves in the equatorial Pacific, J. Geophys. Res., 89, 10431-10440, 1984.

Legeckis. R.. Long waves in the eastern equatorial Pacific Ocean: A view from a geostationary satellite, Science, 197, 1197-1181, 1977.

Legeckis, R., W. Pichel, and G. Nesterczuk, Equatorial long waves in geostationary satellite observations and in a multichannel sea surface temperature analysis, Bull. Am. Meteorol. Soc., 64, 133-139, 1983. 
Miller, L., D. R. Watts, and M. Wimbush, Oscillations of dynamic topography in the eastern equatorial Pacific, J. Phys. Oceanogr., in press, 1985.

Philander, S. G. H., Instabilities of zonal equatorial currents, 2, J. Geophys. Res., 83, 3679-3682, 1978a.

Philander, S. G. H., Forced oceanic waves, Rev. Geophys., 16, 15-46, $1978 b$.

Weisberg, R. H., and A. M. Horigan, Lowfrequency variability in the equatorial Atlantic, J. Phys. Oceanogr., 11, 913-920, 1981 .

Weisberg, R. H., A. M. Horigan, and C. Colin, Equatorially trapped Rossby-gravity wave propagation in the Gulf of Guinea, $J$ Mar. Res., 37, 67-86, 1979.

George Philander is with the Geophysical Fluid Dynamics Laboratory, National Oceanic and Atmospheric Administration (NOAA), Princeton University, Princeton, $N . J$. David Halpern is with the Pacific Marine Environmental Laboratory, NOAA, Seattle, Wash. Donald Hansen is with the Atlantic Oceanographic and Meteorological Laboratories, NOAA, Miami, Fla., and also with the Cooperative Institute for Marine and Atmospheric Studies of the University of Miami. Richard Legeckis is with the National Environmental Satellite Data and Information Service, Washington, $D$. C. Laury Miller, Randolph Watts, and Mark Wimbush are at the Graduate School of Oceanography, University of Rhode Island, Kingston. Carl Paul is with the Cooperative Institute for Marine and Atmospheric Studies of the University of Miami. Robert Weisberg is with the Department of Marine, Earth, and Atmospheric Sciences, North Carolina State University, Raleigh.

\section{Information Report}

\section{U.S. WOCE Working Groups}

\section{PAGE 155}

As a key part of planning for a U.S. component of the World Ocean Circulation Experiment (WOCE), the Scientific Steering Committee (SSC) has established several U.S. WOCE Working Groups (WG). Generally, these working groups are charged with recommending which data and technical or scientific developments are required to attain the scientific objectives. The present status of these working groups is reviewed here.

\section{Working Group on Atmosphere-Ocean Exchange}

This working group is charged with planning functions that are needed to achieve the objective of improved basic descriptions of the surface boundary conditions and the exchanges of physical properties with the atmosphere, and to establish their uncertainties. These functions include assessments of present capabilities, encouragement of analyses and developments needed to improve these capabilities, and recommendation of data collection, processing, and management systems needed to meet the objective.

The working group will maintain liaison (through common membership) with related groups of TOGA (Tropical Ocean Global Atmosphere) and NASA science groups. Chaired by William Large (NCAR), its members include D. Chelton (OSU), M. Freilich (JPL), C. Gautier (SIO), E. Harrison (MIT), T. Liu (JPL), and P. Taylor (IOS/UK) (for all abbreviations not defined in text, see glossary).

\section{Working Group on Ocean Surface Layer}

This working group, chaired by Roland deSzoeke, is charged with recommending WOCE activities to meet the following objective: to describe the upper boundary layer of the ocean adequately for quantitative estimates of large-scale vertical exchange of mass, heat, fresh water, buoyancy, momentum, vorticity, and chemical tracers between the surface layers (and the atmosphere) and the ocean interior, as well as the horizontal transports of some of these quantities and their divergences. This work will involve consideration of the physics of operative processes, recommendations of data needed to adequately describe such processes for WOCE goals, and suggested strategies for obtaining such data.

The following potential members were invited to the organizational meeting held at the Scripps Institution of Oceanography on January 25, 1985: Andrew Bennett (IOS/BC), David Halpern (NOAA/PMEL), William Large (NCAR), James Luyten (WHOI), Clayton Paulson (OSU), Lynne Talley (SIO), Robert Weller (WHOI), and Warren White (SIO). A report of that meeting will be available soon.

\section{Working Group on Numerical Modeling}

A WOCE Working Group on Numerical Modeling (WGNM) has been established to serve as a community forum for the discussion of progress in numerical general circulation modeling and its relationship to WOCE design and data analysis and as an advisory body on resource and manpower requirements for large-scale ocean modeling. More specific terms of reference are under consideration by the WG membership. Dale Haidovgel (NCAR) is the WGNM Chairman. Other members include Kirk Bryan (GFDL/ NOAA), Mark Cane (LDGO), Young-June Han (OSU), Ed Harrison (MIT), William Holland (NCAR), Harley Hurlburt (NORDA), James J. O'Brien (FSU), Jorge Sarmiento (GFDL/NOAA), Bert Semtner (NCAR), and Allan Robinson (Harvard).

The first meeting was held at NCAR on December 10, 1984. The meeting had two purposes: to review the status of large-scale modeling in the United States and its role in WOCE and to discuss the issues of manpower and computer resources. The WGNM conclusions on these latter issues served as input to a UCAR meeting held the following day to discuss computing resources for the U.S. ocean modeling community. A WG meeting report will be available soon.

In preparation for the U.S. WOCE preliminary scientific plan, the WGNM is presently considering the likely relations between models and data in WOCE. The questions being considered include the following: Which specific observational data sets have been most useful in the past in running and evaluating models of the large-scale ocean circulation? Which data sets, and which level of accuracy, are desirable as a result of WOCE? Finally, which specific modeling activities are now needed in preparation for the acquisition and utilization of these data sets? A summary discussion of these issues is being prepared for the WOCE SSC.

\section{Working Group on Experimental Design for Measuring Geostrophic Circulation}

The objective of this WG is to pursue individual research and group discussion on the design of WOCE for the objective of measuring the geostrophic general circulation of the oceans. This is a small group with expertise and interests covering measurement techniques and analyses for the geostrophic circulation. They have begun the process of formulating a quantitative framework for constructing and evaluating experimental designs. Meetings will be few. The present membership consists of $\mathrm{H}$. Bryden (WHOI), R. Davis (SIO), J. Luyten (WHOI), Chairman J. McWilliams (NCAR), and J. Price (WHOI).

\section{Working Group on Technology Development}

An array of new or improved techniques, instrumentation, platforms, and facilities will be needed for the WOCE experimental program. The U.S. WOCE Technology Working Group is charged with planning and coordinating activities to insure the availability of these capabilities when they are needed. This WG is organized with a small membership but with a large advisory committee to ensure a range of expertise from academia and industry. The smaller group is required to provide formal guidance by determining directions for development, making recommendations regarding proposal activities, etc. The advisory committee, which is available to lend expertise and advice to the WG chairman, Robert Heinmiller, is open to all interested parties. By agreement of the international WOCE Scientific Steering Group, the U.S. Technology Development Working Group is also the lead group for technology development for international WOCE.

Working Group activities will involve

- Identification of WOCE needs in technology improvement or new development

- Identification of existing development efforts of interest to WOCE

- Identification of individuals to carry out needed development work which is not already underway

- Where necessary, coordination of interrelated development efforts

- Planning for the transfer of appropriate technology to commercial production

- Evaluation for WOCE needs of existing commercial products

- Identification of and planning for necessary operational facilities

- Recommendations to the WOCE Scientific Steering Committee on technology issues Working Group members are Richard Blidberg (UNH), Robert Chase (WHOI), Russ Davis (SIO), Curt Ebbesmeyer (EvansHamilton, Inc., Seattle, Wash.), Robert Heinmiller (Omnet Inc., Boston, Mass.), and Dale Pillsbury (OSU). Corresponding international members are Pierre Tillier (Centre Oceanologique de Bretagne, France) and Juergen 